\title{
A COLABORAÇÃO FORTALECENDO A PRÁTICA
}

\author{
Caroline Machado Cortelini \\ corteli@mail.ufsm.br
}

Claiton José Grabauska

grabauska@smail.ufsm.br

\section{RESUMO}

Este artigo propõe-se compartilhar nossas reflexões e experiências referentes à construção de uma prática colaborativa, apontando a colaboração como categoria orientadora das práticas educativas. Norteamo-nos pelos fundamentos da educação dialógico-problematizadora (Freire, 1988) e na investigação-ação educacional (Carr e Kemmis, 1988), a fim de propor uma perspectiva de educação crítica que se alicerce sobre o diálogo, a colaboração e a auto-reflexão. Aponta-se a colaboração como possibilidade de melhora e transformação das práticas educativas e do resgate do poder profissional. Ressalta-se o papel do professor como intelectual transformador, investigador da sua prática, na busca de compreendê-la, melhorá-la e transformá-la. Assinala-se a investigação-ação educacional como processo de investigação que atua transformativamente no âmbito do trabalho individual e coletivo. Ela cria condições que permitem a constituição de comunidades auto-criticas de investigação, composta por pessoas que participam e colaboram em todas as fases do processo de investigação. Delineamos algumas considerações referentes à prática educativa no sentido de antevermos a possibilidade de através de um processo colaborativo compreendê-las e transformá-las, pensando em transformação social efetiva, a partir da transformação das práticas de grupos organizados.

\section{INTRODUÇÃO}

O propósito que nos leva produzir este artigo é o de compartilhar nossas reflexões e experiências no que concernem à construção de uma prática colaborativa. Buscamos com isso expor os pressupostos que norteiam nosso "quefazer". Discute-se aqui algumas questões pertinentes à prática pedagógica onde procuramos demarcar nosso entendimento referente a esta, bem como apresentar e analisar o que temos realizado.

Busca-se aqui sistematizar algumas reflexões sobre uma questão premente que vemos na educação, ou uma possibilidade a ser proposta como categoria orientadora das práticas educativas, sendo esta a colaboração. Trazemos como referência nossa prática educativa, em que temos buscado apontar algumas alternativas no sentido de conferir ao nosso "quefazer" (Freire, 1988) a característica da colaboração. 
Para tanto, nosso trabalho fundamenta-se basicamente pela perspectiva da prática educativa como investigativa. Nesse sentido, buscamos os fundamentos na educação dialógico-problematizadora (Freire, 1988) e na investigação-ação educacional (Carr e Kemmis, 1988), a fim de propor uma perspectiva de educação crítica que se alicerce sobre o diálogo, a colaboração e a auto-reflexão. Nesse contexto, educadores convertem-se em investigadores ativos-críticos de suas práticas na busca de compreendê-las, melhorá-las e transformá-las.

\section{A COLABORAÇÃO COMO PRESSUPOSTO PARA UM "QUEFAZER" CRÍTICO}

Atuar em uma perspectiva colaborativa implica compartilhar. Isso implica a cedência e a conquista, ceder um pouco do meu espaço, ou conquistar, buscar ampliar o espaço. Vem a ser, tornar o que é meu, nem mais somente meu, e o que não é de ninguém tornar de todos. Também tem o significado de compartilhar as angústias, o "peso nas costas", as incertezas, bem como as realizações, as certezas, as possibilidades.

A colaboração pode tornar-se uma categoria a imprimir possibilidades transformativas, de melhora e transformação das práticas educativas, ao ser concebida como uma prática. Podemos localizá-la como uma possibilidade de fortalecimento profissional (Nascimento, 1998) por parte dos educadores, o resgate do poder profissional, na medida em que consideramos a força da coletividade. Atuar colaborativamente possibilita aos professores organizarem-se em seus espaços de atuação. Pressupõe, para nós, definir conjuntamente um norte, os pressupostos que queremos para guiar nossas práticas, e a partir daí encaminhar juntos o trabalho.

A colaboração é entendida como trabalhar juntos e não, simplesmente, ocupar o mesmo espaço e fazer as mesmas tarefas. Ela significa auxílio e crítica mútuos, construídos a partir do respeito pelo nosso igual.

Atuar colaborativamente pode ser uma alternativa para o resgate da autonomia do professor, do papel atuante em sua prática. Giroux (2002) afirma que aos professores tem sido delegada a tarefa de meros executores, as reformas educativas têm nos 
reduzido à categoria de técnicos superiores, encarregados de cumprir definições e objetivos determinados por outros que estão alheios à realidade cotidiana da sala de aula. Dessa forma, o professor perde muito do seu poder, que perpassa por decidir e encaminhar sua prática.

Vemos a partir daí a necessidade de nos organizarmos coletivamente a fim de melhorar as condições de trabalho e concretizar melhoras na educação. Nessa perspectiva, ressalta-se o papel do professor como profissional da reflexão, como intelectual transformador, de acordo com Giroux (2002). Ainda nesse sentido, apontam Carr e Kemmis (1988) a possibilidade dos educadores constituírem-se em investigadores ativos-críticos de suas práticas.

Um primeiro passo para atuar em uma perspectiva de colaboração poderia ser como profissionais da educação descobrir o interesse sobre o que fazemos, sobre como encaminhamos nossas práticas. Assim, cabe a nós investigar no que podemos melhorar, no que podemos auxiliar, no que podemos ser auxiliados. Isto envolve, evidentemente, questões técnicas de nossa profissão - metodologias de ensino, técnicas, organização curricular. Mas envolve, antes de tudo, uma mudança de postura quanto ao ensinar e ao aprender. Envolve desenvolver uma prática que seja coerente com os valores que temos.

Podemos dessa forma, então, ver o professor como investigador da sua prática, na busca de compreendê-la, melhorá-la e transformá-la. Nesse sentido, afirma Freire (1999) que não há ensino sem pesquisa e nem pesquisa sem ensino, e estes "quefazeres" se encontram intrinsecamente atrelados um ao outro. Entendemos que a investigação, a capacidade de indagação, faz parte da própria natureza da prática educativa e torna-se inegável que o professor, em seu processo permanente de formação, se assuma, porque professor, como pesquisador. E realize como processo permanente a investigação de seu "quefazer".

Giroux (2002) aponta como uma das maneiras de repensar e redefinir a natureza do trabalho docente, conceber tais profissionais como intelectuais transformativos. Segue o autor delimitando as potencialidades da categoria de intelectual - esclarecer as condições ideológicas e práticas do "quefazer" educativo; contribuir para elucidar o 
papel que desempenham na legitimação dos diversos interesses políticos, econômicos e sociais através das concepções que utilizam.

A visão de professores como intelectuais potencializa uma consistente crítica teórica às ideologias tecnocráticas e instrumentais subjacentes à teoria educativa, a qual separa a conceitualização, planejamento e elaboração do currículo dos processos de execução. Nesse sentido defendemos que urge fomentarmos a capacidade de organização dos profissionais da educação no sentido de nos capacitarmos para repensar e reformar as condições atuais da educação, bem como desenvolver e assumir o potencial transformador.

Esse potencial transformador refere-se a se tornarem investigadores ativos das próprias práticas. A categoria de investigação, para nós, potencializa desenvolver o processo de reflexão sistematizada sobre/na/para a prática, que vem a ser uma alternativa para melhor compreendê-la e modificá-la. Nesse sentido voltamos a Giroux (2002, p.10) que afirma que um componente da transformação é o "conseguir que o pedagógico seja mais político e o político seja mais pedagógico", ou seja, é assumir a dimensão política, por isso não neutra da educação, e seus condicionantes sociais. Assumir a educação como um dos instrumentos de transformação social.

Os intelectuais transformativos necessitam desenvolver um discurso que conjugue a linguagem da crítica com a da possibilidade, de forma que os educadores sociais reconheçam que têm a possibilidade de introduzir algumas mudanças. (Giroux: 2002, p.10).

É necessário considerar que um projeto colaborativo poderá se efetivar na prática educativa com o envolvimento e o comprometimento dos educadores. Isso implica a disponibilidade de estes tomarem suas práticas como objetos de investigação e se proporem a realizar um processo de reflexão estruturado, que oriente as transformações necessárias. O educador, nesta situação, coloca-se na posição de quem está constantemente aprendendo com sua prática, que esta jamais estará pronta e acabada e sim estará sendo sempre refeita e reorganizada em cada contexto.

\section{A INVESTIGAÇÃO DAS PRÁTICAS COMO INSTÂNCIA TRANSFORMADORA}


Diante disso, apontamos a investigação-ação educacional como concepção que pode potencializar a organização da ação educativa e a implementação de transformações em nossas práticas. Pode-se, desse modo, evidenciar-se melhoras reais dos entendimentos que se tem das próprias praticas e das situações concretas que estas produzem. Vemos esta concepção como potencializadora e organizadora da autoreflexão que se realiza, orientada para a transformação das práticas.

Um dos mais importantes resultados de um processo de investigação-ação é o de potencializar, como refere Angulo Rasco (1990), o conhecimento profissional e a capacidade de reflexão e juízo dos participantes. É, portanto, um processo de geração de conhecimento e formação e desenvolvimento profissional para os educadores. Possibilita uma proposta formativa na prática e para a prática.

Tal concepção de investigação é um processo coletivo que atua transformativamente no âmbito do trabalho individual e coletivo. Atuar na perspectiva da investigação-ação implica agir, observar e refletir de forma mais cuidadosa, mais sistemática e mais rigorosa, produzindo daí um novo conhecimento que possibilite a mudança das práticas dos envolvidos. Kemmis e McTaggart (1988) oferecem uma definição de investigação-ação que reforça a necessidade de mudanças construídas no coletivo:

\footnotetext{
A investigação-ação é uma forma de indagação coletiva empreendida por participantes em situações sociais com objetivo de melhorar a racionalidade e a justiça de suas práticas sociais ou educativas, assim como sua compreensão dessas práticas e das situações em que estas têm lugar (KEMMIS e McTAGGART, 1988: 9).
}

Assim, embora seja uma tarefa coletiva, a investigação-ação está ancorada, num primeiro momento, nas ações e reflexões dos indivíduos que realizam uma prática social. Desta forma, é uma concepção de investigação que, sem desprezar ou menosprezar a teoria, encontra sua validade na prática.

Vemos na investigação-ação educacional os subsídios necessários para trabalhar com as necessidades educacionais e sociais, apontando assim, possibilidades concretas para as práticas. Ela cria condições que permitem a constituição de comunidades autocríticas de investigação, composta por pessoas que participam e colaboram em todas as fases do processo de investigação - desse modo todos os 
envolvidos são sujeitos de suas práticas. As práticas, os entendimentos que temos destas e o que queremos alcançar, as situações, são algo próprio do investigador e que ele está comprometido em criar.

A investigação-ação educacional vem a ser um modo de viabilizar o trabalho coletivo de desenvolver uma prática criticamente informada, possibilitando aos sujeitos envolvidos aprender de sua própria experiência. Sendo assim, esta concepção de investigação traz consigo uma característica que pode transformar consideravelmente o trabalho dos educadores, propondo a colaboração como condição para se realizar. Desse modo, se entrevê a possibilidade de os educadores se apoderarem do processo de elaboração e execução de suas práticas, definindo concepções, métodos e ações conjuntamente.

Nesse sentido Carr e Kemmis (1989, p.229) defendem que: "Na investigação-ação colaborativa, o desenvolvimento de teorias educacionais tem lugar como parte integrante do desenvolvimento da educação mesma: o desenvolvimento de políticas educacionais tem lugar como parte integrante do processo democrático de reforma da educação". Assim, fica afirmada a criação de comunidades colaborativas de autoreflexão a fim de se alcançar uma melhor compreensão da prática educativa e melhorar a educação.

Como bem afirma Kemmis (1988), não basta apenas a organização de comunidades, mas o interesse comum na emancipação, implicando uma perspectiva diferenciada da vida social. Nessa forma, o diálogo legitima o conhecimento proveniente da autoreflexão, visto que os envolvidos são sujeitos de seu próprio processo de educação.

\section{CONTANDO UMA HISTÓRIA DE COLABORAÇÃO}

No Centro Educacional Infantil Casinha da Criança, temos aprendido, no compartilhar de nossas práticas, que é possível quando atuamos no coletivo ampliar nossas compreensões e, pode-se dizer, nos aventurarmos naquilo que não nos é tão conhecido, ou seja, nos desafiamos a transformar nossas práticas. Desse modo temos nos apropriado de um conhecimento novo que nos permite encaminhar o trabalho. 
Após um ano de trabalho, fala uma das professoras: "Agora que eu estou entendendo o que é ensinar e o que é aprender".

Considero que a colaboração/investigação foi o elemento central potencializador de nosso trabalho, pois a dimensão da sua concretização se deu pela disponibilidade dos envolvidos de conceberem sua prática como objeto de investigação. O elemento essencial foi exatamente a disponibilidade para aprender, para buscar compreender a prática educativa. Nesse sentido, percebemos que obtivemos algumas conquistas no decorrer de nosso trabalho, com relação à ampliação da compreensão das educadoras sobre sua prática, a disponibilidade de buscar o conhecimento.

Temos experienciado a investigação-ação educacional como possibilidade de viabilizar o caráter colaborativo da prática educativa. Carr e Kemmis (1989) defendem que os professores devem tornar-se investigadores de suas próprias práticas, constituindo comunidades de investigadores-ativos-críticos em que a investigaçãoação volta-se para as transformações coletivas. Inaugura-se assim o caráter colaborativo da investigação-ação, a partir da compreensão de que o fortalecimento das comunidades investigativas se dará a partir do fortalecimento do trabalho conjunto, em que os professores estarão unidos pelo mesmo propósito de compreensão e transformação de sua realidade.

O trabalho realizado possibilitou importantes aprendizagens aos envolvidos, no que se refere à organização e implementação de uma proposta diferenciada na escola. Salientamos a melhora na sistematização e registro dos planejamentos; na articulação dos temas e conteúdos; no desenvolvimento do diálogo; na investigação temática (foi uma grande aprendizagem retirar os temas do contexto e das vivências do grupo, a partir daí pode-se perceber o maior envolvimento das crianças com o trabalho proposto).

Consideramos que conjuntamente estamos ampliando nossos conhecimentos sobre a prática educativa, fortalecendo-nos pela colaboração. Esse processo investigativo/colaborativo tem possibilitado nossa formação continuada, mesmo que em instâncias diferentes (seja no mestrado, seja para as professoras da escola na melhora de suas práticas — na educação continuada informal). 


\section{BREVES CONSIDERAÇÕES}

Pensar a investigação-ação como suporte formador implica necessariamente a atuação coletiva. Vamos além do coletivo ao propormos a colaboração, pois esta implica um atuar guiado por propósitos comuns, implica o auxiliar-se mutuamente, apropriar-se de instrumentos que fortaleçam o grupo.

Consideramos que a prática educativa tem sido um ato extremamente solitário. Contudo, educar não pode ser um ato solitário, e sim um ato em comunhão, como vemos em Freire (1988, p.69), "ninguém educa ninguém, como tampouco ninguém educa a si mesmo, os homens se educam em comunhão mediatizados pelo mundo". Ou seja, é da natureza da educação que esta se dê em comunhão. Entendemos que Freire, ao utilizar o termo comunhão, propõe a colaboração.

Podemos vislumbrar então o potencial da educação como um ato compartilhado, como tarefa coletiva de sujeitos imbuídos de um mesmo ideal — preferencialmente emancipatório. Quando a escola passa a ser de todos, quando abrimos os limites da sala de aula para a comunidade inteira, quando todos educadores entrelaçam suas crenças na realização de uma prática transformadora e no processo de compartilhar suas reflexões vão apropriando-se de um conhecimento legítimo que lhes pertence, vão apropriando-se de uma prática autêntica validada pela colaboração e pelo diálogo.

Partindo do pressuposto de uma educação dialógica, a educação torna-se uma prática compartilhada. Ampliando os limites da sala de aula, o espaço é a escola, a sociedade como um todo, portanto não se trata mais apenas de pensar a "minha prática". Mas trata-se de juntos pensarmos as nossas práticas, compreendê-las e transformá-las, pois assim podemos pensar em transformação social efetiva, a partir da transformação das práticas de grupos organizados. Como bem vemos em Freire (1989, p. 78), "O diálogo é este encontro dos homens, mediatizados pelo mundo, para pronunciá-lo, não se esgotando, portanto, na relação eu-tu."

Acreditamos que melhoras reais na prática educativa se darão, bem como transformações efetivas, a partir de um movimento de compreender a própria prática 
como elemento de investigação. Para tanto apontamos acima a viabilidade desse trabalho no coletivo, implicando a colaboração dos envolvidos. Assim, esse "quefazer" significará o desafio de ultrapassar as limitações do grupo e passar aos poucos a partir do que cada um traz, ir elaborando o trabalho. Significa deixar algumas idéias para trás, aceitar mudar o modo de agir.

\section{BIBLIOGRAFIA}

ANGULO RASCO, J. Félix. Investigación-acción y curriculum: una nueva perspectiva en la investigación educativa. In: Investigación en la Escuela, n¹1, Barcelona, 1990.

CARR, Wilfred e KEMMIS, Sthephen. Teoría Crítica de la Ensenanza - La Investigación/Acción en la formación del professorado. Barcelona: Marinez Roca S. A., 1988.

FREIRE, Paulo. Pedagogia do oprimido.18a ed. São Paulo: Paz e Terra, 1988. Pedagogia da autonomia: Saberes necessários a prática educativa. 12 ${ }^{\mathrm{a}}$ ed. São Paulo: Paz e Terra, 1999.

GIROUX, Henry A. Los profesores como intelectuales transformativos. Fórum Mundial de Educação, 2002. Disponível em: http://habitantes.elsitio.com/llens.

KEMMIS, Stephen. El curriculum: más allá de la teoría de la reproducción. Madrid: Morata, 1988.

KEMMIS, Stephen e MCTAGGART, Robin. Cómo planificar la investigaciónacción. Barcelona: Editorial Alertes, 1988.

NASCIMENTO, C. R. Esclarecimento e Fortalecimento do Professor: vivência num programa de investigação-ação educacional emancipatória num Curso Normal da rede pública estadual da Santa Catarina. Dissertação de Mestrado, UFSM/CE/PPGE, Santa Maria, RS, 1998. 